\title{
Effects of subcutaneous carbon dioxide on calcitonin gene related peptide and substance $P$ secretion in rat skin $^{1}$
}

\author{
Erica Calcagno Raymundo', Bernardo Hochman ${ }^{\text {II }}$, Michele Akemi Nishioka ${ }^{\mathrm{III}}$, José Octávio Gonçalves de Freitas ${ }^{\mathrm{IV}}$, Jéssica \\ Ruivo Maximinov , Gerson Chadi ${ }^{\mathrm{VI}}$, Lydia Masako Ferreira ${ }^{\mathrm{VII}}$
}

\section{DOI: http://dx.doi.org/10.1590/S0102-86502014000400002}

IFellow Master degree, Postgraduate Program in Plastic Surgery, Sao Paulo Federal University (UNIFESP), Sao Paulo, Brazil. Conception and design of the study, analysis and acquisition of data, technical procedures, manuscript preparation.

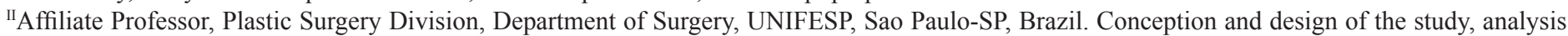
and interpretation of data, technical procedures, critical revision.

II'Fellow Master degree, Postgraduate Program in Plastic Surgery, UNIFESP, Sao Paulo-SP, Brazil. Acquisition of data, technical procedures.

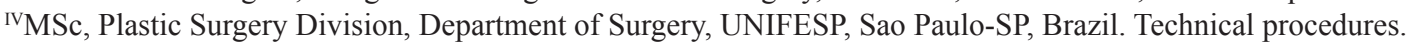

${ }^{\mathrm{v}} \mathrm{PhD}$, Neuroregeneration Center, Department of Neurology, School of Medicine, Sao Paulo University (USP), Sao Paulo-SP, Brazil. Technical procedures, analysis and acquisition of data.

${ }^{\mathrm{VI} F u l l}$ Professor, Neuroregeneration Center, Department of Neurology, School of Medicine, USP, Sao Paulo-SP, Brazil. Technical procedures, analysis, acquisition and interpretation of data.

${ }^{\mathrm{VII}}$ Full Professor, Head of Plastic Surgery Division, Department of Surgery, UNIFESP, Sao Paulo-SP, Brazil. Manuscript writing, critical revision.

\begin{abstract}
PURPOSE: To investigate the subcutaneous injection of carbon dioxide $\left(\mathrm{CO}_{2}\right)$ on neuropeptides Calcitonin Gene-Related Peptide (CGRP) and Substance P (SP) secretion in rat skin.

METHODS: Fifty-six Wistar-EPM rats were distributed in two groups: one for CGRP analysis, the other for SP analysis. Each group was subdivided into four subgroups: control (Cont), control with needle (ContNd), $\mathrm{CO}_{2}$ injection $\left(\mathrm{CO}_{2} \mathrm{Inj}\right)$ and atmospheric air injection (AirInj) - with seven animals each. Sample analyses of partial skin were conducted by Western Blotting (WB).

RESULTS: In SP group, there was a decrease in the amount of neuropeptides in subgroups $\mathrm{CO}_{2} \mathrm{Inj}$ and AirInj. Similarly, in CGRP group, there was a decrease in the amount of pro-CGRP neuropeptides $(15 \mathrm{kDa})$ in subgroups $\mathrm{CO}_{2}$ Inj and AirInj; Nevertheless, there was no decrease in the amount of CGRP $(5 \mathrm{kDa})$ in any subgroups.
\end{abstract}

CONCLUSION: Subcutaneous injection of $\mathrm{CO}_{2}$ and atmospheric air decreased the amount of Substance P and pro-Calcitonin GeneRelated Peptide $(15 \mathrm{kDa})$ neuropeptides in rat skin.

Key words: Carbon Dioxide. Substance P. Calcitonin Gene-Related Peptide. Neurogenic Inflammation. Skin. Rats. 


\section{Introduction}

Carboxytherapy is a technique originated in 1930 in which carbon dioxide $\left(\mathrm{CO}_{2}\right)$ is injected through a needle into the subcutaneous tissue. It is estimated that it increases tissue circulation and oxygenation. Lesions caused by the gas trigger a local inflammatory process which results in tissue healing, represented by angiogenesis and fibrogenesis. These effects may occur due to an increase in capillary blood flow triggered by hypercapnia, by a decreased consumption of cutaneous oxygen or by a rightward shift of the oxygen $\left(\mathrm{O}_{2}\right)$ dissociation curve (Bohr effect) $)^{1}$. It is known that intranasal $\mathrm{CO}_{2}$ may inhibit trigeminal neuronal activation (in rats) and suppress in vitro calcitonin gene-related peptide (CGRP) release ${ }^{2}$. Based on this assumption, the efficiency of intranasal noninhaled $\mathrm{CO}_{2}$ was investigated in the treatment of seasonal allergic rhinitis $(\mathrm{SAR})^{3}$. Although the mechanism involved in the therapeutic effect of $\mathrm{CO}_{2}$ on allergic rhinitis has not been examined, previous reports ${ }^{2}$ associate the administration of $\mathrm{CO}_{2}$ in buffered media to both neuronal and CGRP release inhibition, probably due to the inhibition of calcium channels activities and subsequent increase in intracellular calcium. Activation of trigeminal nerves was related to SAR pathogenesis, followed by mast cell activation and release of inflammatory mediators. Activation of trigeminal nerves also causes local release of neuropeptides, including CGRP ${ }^{4}$.

The concept of neurogenic inflammation lies in the fact that, when a nociceptive stimulus moves towards medullary processing, there is also an antidromic axon reflex to the $\mathrm{A}$ and $\mathrm{C}$ fibers nerve endings with consequent release of pro-inflammatory neuropeptides, such as CGRP, SP, neurokinin A (NKA), Vasoactive Intestinal Peptide (VIP), among others. Then, due to a cascading effect, there is inflammatory activation, vasodilation, chemoreceptors activation, chemotaxis of inflammatory cells, like neutrophils, lymphocytes, mast cells, keratinocytes, fibroblasts and melanocytes, and release of several factors such as histamine, TNF- $\alpha$, prostaglandins, leukotrienes and interleukins ${ }^{5,6}$. The clinical manifestation consists of pruritus and a characteristic erythema at the site of the stimulus, promoting a fast start of the tissue inflammation process $^{7,8}$. Thereby, neurogenic inflammation is the first event on the inflammatory phase of the healing process.

$\mathrm{CO}_{2}$ injection technique is currently used in healthcare; however, there are still knowledge gaps in its mode of action, especially in the neurogenic inflammation phase. Despite constant dissemination of the carboxytherapy technique and enough evidence for $\mathrm{CO}_{2}$ application in scars and cellulite, to date there is no literature with the recommended international scientific rigor ${ }^{9}$. Since no studies were found which correlate cutaneous neuropeptide concentration, specifically SP and CGRP, after $\mathrm{CO}_{2}$ subcutaneous injection, the objective of this study was to investigate the action of carboxytherapy on SP and CGRP neuropeptide secretion in rat skin.

\section{Methods}

Research approved by the Ethic Committee of Sao Paulo Federal University [CEP 1695/10].

Fifty-six adult (eight weeks old) male Wistar-EPM (Rattus norvegicus) rats weighing 250-350g were used. All animals were housed in individual plastic cages with metal cover to place the container for water and commercial feed, consumed ad libitum. The environment was kept under constant temperature $\left(22 \pm 1^{\circ} \mathrm{C}\right)$, humidity and $12: 12$ hour lightdark cycle, and the animals had one week for adaptation before experimental manipulation.

The animals were weighted and randomly distributed (www.randomization.com) into four subgroups of seven rats for each neuropeptide type, a total of 28 animals to quantify CGRP (15 kDa pro-CGRP and $5 \mathrm{kDa}$ CGRP) and 28 to SP. All the animals were submitted to trichotomy, with a 1 hour wait before conducting the procedures The animals were distributed into the following subgroups: Subgroup 1 Control (Cont), no needle perforation; Subgroup 2 - Control with Needle (ContNd), with hypodermic needle perforation; Subgroup $3-\mathrm{CO}_{2}$ Injection $\left(\mathrm{CO}_{2}\right.$ Inj), with carbon dioxide injection; Subgroup 4 - Atmospheric Air Injection (AirInj), with atmospheric air injection.

After trichotomy, two points (A1 and A2) were marked in each animal using a dermographic pen, representing a line segment " $A$ " located in the dorsal midline, $2 \mathrm{~cm}$ below the transverse line at the lower angle of the scapula. The needle puncturing for gas injection was on the central point marked at $1.5 \mathrm{~cm}$ from the dorsal midline, halfway down the line segment A1 - A2 (Figure 1). 


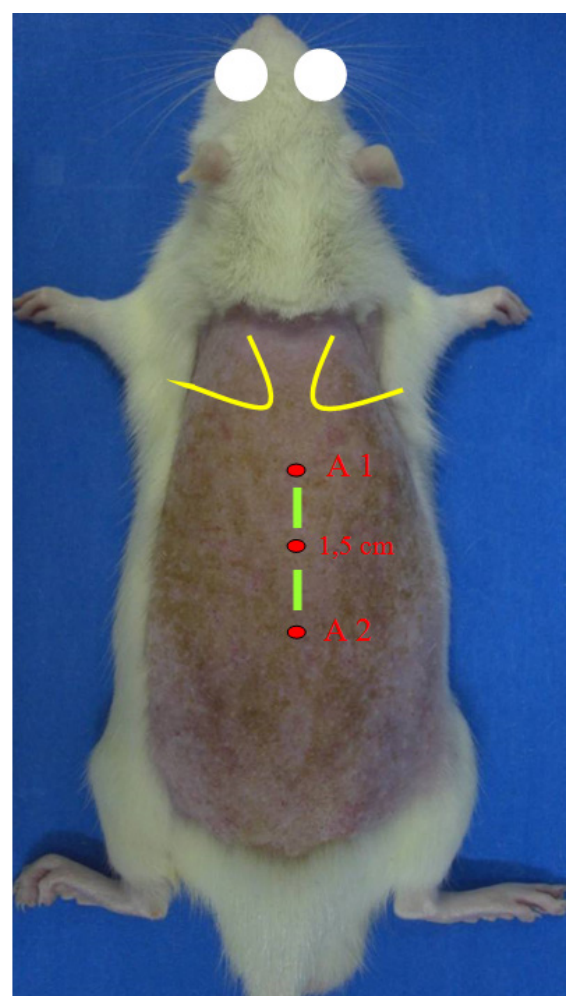

FIGURE 1 - Determining the gas injection point. Marking line segment A through A1 and A2 points. Rat's back hair shaved (scapulae in yellow). A1 and A2 points (red) marked with dermographic pen throughout a $3-\mathrm{cm}$ A line (not marked with pen).

The injections were subcutaneous, with $80 \mathrm{ml} / \mathrm{min}$ flow for 10 seconds, with a total volume of $8 \mathrm{ml}$, using a $30 \mathrm{G} 0.30 \times 4$ $\mathrm{mm}$ hypodermic needle, halfway down the line segment $\mathrm{A}$, with a 90-degree angle (Figure 2).

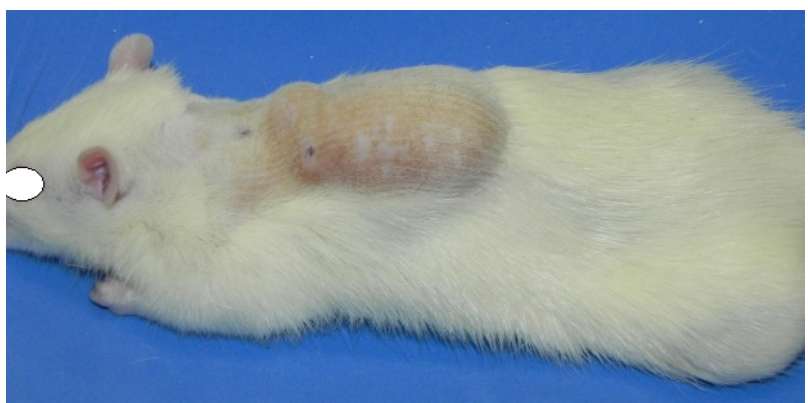

FIGURE 2 - Skin expansion. Animal skin expanded by the injected $\mathrm{CO}_{2}$ and Atmospheric air gases.

Animals were submitted to general anesthesia via intramuscular injection of xylazine hydrochloride $(50 \mathrm{mg} / \mathrm{kg})$ and ketamine $(100 \mathrm{mg} / \mathrm{kg})$ at the ratio of $1: 2$ injected $(1 \mathrm{ml} / \mathrm{kg})$ into the right gastrocnemius muscle. After anesthetic induction, animals were placed in the prone position and their back hair was removed with an electric hair trimmer (WAHL ${ }^{\circledR}$ ).
For sample exeresis, all animals were submitted to painless assisted death by anesthetic overdose (five times the posology dose), followed by section of the great cervical vessels.

In Subgroup 1, the partial skin sample was removed 60 minutes after hair removal (waiting time for animals from all subgroups to conduct experimental procedures). However, in Subgroups 2, 3 and 4, besides the 60-minute interval after hair removal to begin experimental procedures, skin samples were removed 21 minutes after the end of experimental procedures for CGRP quantification and 14 minutes for SP quantification, following results of a previous pilot study.

Circular incisions were made on the skin of all animals until the epidermis and the superficial dermis were marked using a 4-mm-diameter punch. An electrical dermatome (Padgett ${ }^{\circledR}$ ) was then used to remove rectangular partial skin samples. A distance of at least $1 \mathrm{~cm}$ was maintained from the margins surrounding the area marked with the punch for a constant thickness of $500 \mu \mathrm{m}$ - the samples' size and shape were then standardized (Figures 3 to 5).

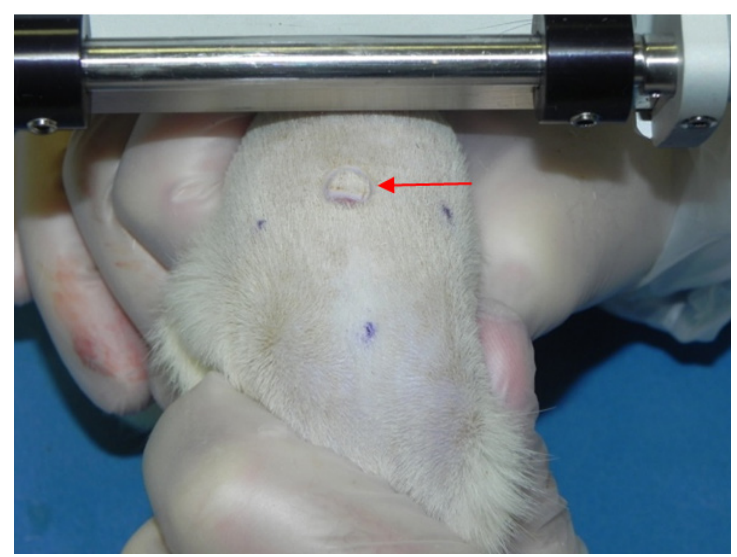

FIGURE 3 - Electrical dermatome. Animal's back presentation and total skin removal with electrical dermatome. In the middle, the 4-mm area marked by the punch (arrow).

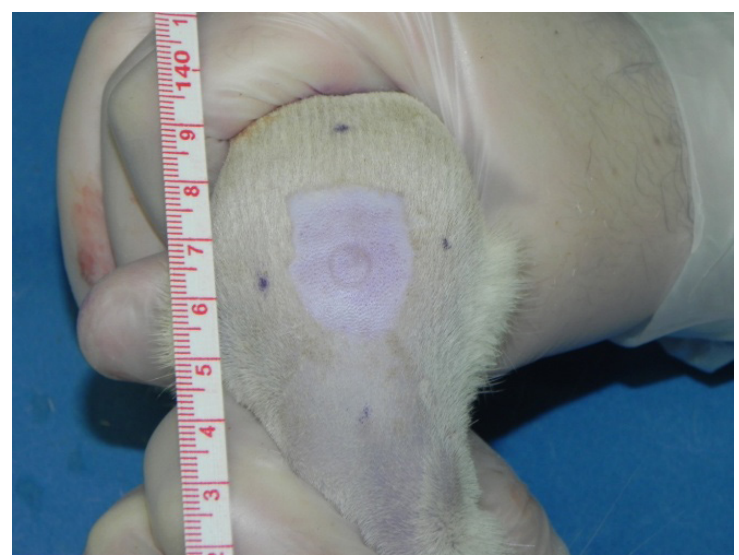

FIGURE 4 - Partial skin removed. After skin removal for analysis, with the circle marked by the 4-mm surgical punch. 
Samples collected were immediately placed in dry Eppendorf tubes with previously sorted random numbers. These tubes were frozen with dry ice and stored in freezer at $-20^{\circ} \mathrm{C}$ until the Western blotting analysis (Figure 5).
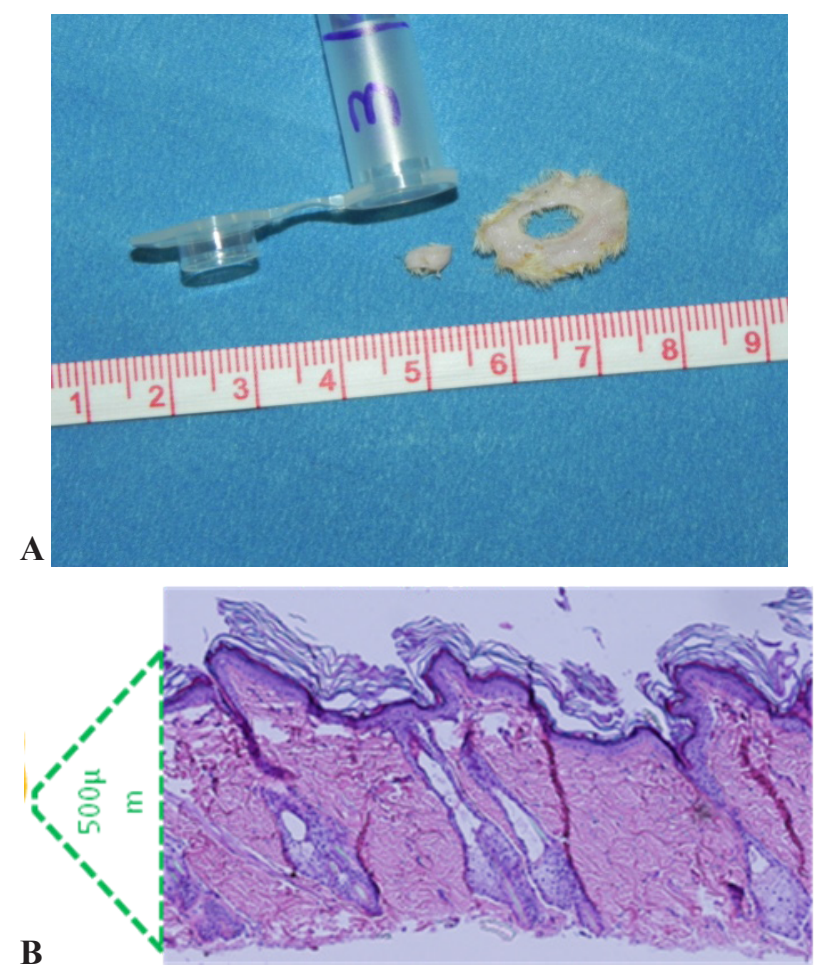

FIGURA 5 - A. Standardized skin sample. Skin sample removed from the middle of line A (after punch) resulting in a 500- $\mu \mathrm{m}$ thick circular shaped partial skin fragment for analysis (kept in an Eppendorf tube to send to Western blotting analysis). B. Photomicrography (x10) of HEstained samples showing constant thickness.

\section{Protein extraction by Western blotting}

Fragments collected from each animal were homogenized in buffered solution for total protein extraction. First, the fragments were lysed and homogenized with a homogenizer using $350 \mu \mathrm{L}$ of lysis buffer consisting of NP40 (1\%), sodium deoxycholate $(0.5 \%)$, sodium dodecylsulphate (SDS, $1 \%)$, edetic acid (EDTA, $1 \mathrm{mmol} / \mathrm{L}$ ), egtazic acid (EGTA, $1 \mathrm{mmol} / \mathrm{L}$ ) and protease-inhibitor cocktail (Sigma, $1 \%$ ) in PBS ( $\mathrm{pH}$ 7.4). After homogenization, the tubes were centrifuged at 14,000 rpm for 20 minutes at 4 ${ }^{\circ} \mathrm{C}$. Supernatants were obtained and the amount of protein was determined according to the Bradford method [10].

Samples were diluted in lysis buffer to obtain $60 \mu \mathrm{g}$ in $25 \mu \mathrm{L}$ of buffer. They were then denatured at $100{ }^{\circ} \mathrm{C}$ for 3 minutes and applied to the $12 \%$ polyacrylamide gel wells for separation. Five $\mu \mathrm{L}$ of molecular weight marker were applied to one of the small wells (Kaleidoscope, pre-colored, Bio-Rad, USA). The running buffer was prepared with trisma $(25 \mathrm{mmol} / \mathrm{L})$, glycine
$(0.2 \mathrm{~mol} / \mathrm{L})$ and $\operatorname{SDS}(0.1 \%)$; the proteins were separated by applying $100 \mathrm{~V}$ for 1 hour and 30 minutes.

After running the gel, the proteins were transferred to polyvinylidene fluoride (PVDF) membrane (Bio-Rad) using a cold transfer buffer with trisma $(25 \mathrm{mmol} / \mathrm{L})$, glycine $(0.2 \mathrm{~mol} / \mathrm{L})$ and methanol (10\%) for 1 hour at $100 \mathrm{~V}$.

The membrane was incubated with blocking solution for the free sites for 15 minutes at room temperature. The blocking solution is composed by $0.05 \%$ milk in tris-buffered saline with Tween-20 (TBS-T). After blocking, the membranes were incubated with primary antibodies: anti-Substance $\mathrm{P}$ polyclonal antibody produced in goats (1/100, Santa Cruz) and anti-CGRP polyclonal antibody produced in rabbits (1/300, Sigma), both diluted in milk (3\%) in TBS-T for 24 hours at $4^{\circ} \mathrm{C}$ and constant stirring. After this incubation, the membranes were washed twice for 10 minutes in TBS-T and incubated with the secondary antibodies, anti-goat and anti-rabbit (1/2.000, GE and 1/10.000, GE, respectively), conjugated to a peroxidase (HRP-conjugated), diluted in milk $(3 \%)$ in TBS-T and incubated for 1 hour at room temperature.

After incubation with the secondary antibodies, the membranes were washed twice in TBS-T and once in trisbuffered saline (TBS) for 10 minutes each. The reaction occurred by incubation with chemiluminescent reagent (Western Lightning Chemiluminescence Reagent Plus, ECL kit, Perkinelmer, USA) for exactly 1 minute. The membranes were exposed to a chemiluminescent-sensitive film (Hyperfilm ECL, Amersham Biosciences) for 30 seconds to 5 minutes, depending on the antibody, and developed according to the manufacturer's instructions.

After development of films, the membranes were washed and submitted to new labeling with antibody to beta-actin in order to normalize protein values. To do so, the membranes were incubated with primary antibody against beta-actin diluted at 1:30.000 (Sigma, USA) in TBS-T with 1\% Bovine Serum Albumin (BSA) for 1 hour at room temperature, then washed twice for 10 minutes with TBS-T and incubated for 45 minutes at room temperature with the secondary antibody (anti-rabbit, HRP-conjugated, Amersham) diluted at 1:10.000 in TBS-T with $1 \%$ BSA. After these incubations, the membranes were washed as previously described, which was followed by reaction and film developing ${ }^{11}$. The films were quantified by optical densitometry using an image analyzing system, as described by Chadi et al. ${ }^{11}$.

SP and CGRP quantification in skin samples were obtained in arbitrary units presented as average, standard deviation, and maximum and minimum values. The KolmogorovSmirnov Test was performed to assess the normality of data. When 
non-normality of data was detected, Wilcoxon Mann Whitney intragroup test was performed. For all tests, a p-value of .05 was considered significant (SPSS software).

\section{Results}

Regarding $15 \mathrm{kDa}$ CGRP secretion, neuropeptide quantification in Control Subgroup (Cont) did not differ from Control with Needle Subgroup (ContNd) (Figure 6). The same happened for the subgroups in which $\mathrm{CO}_{2}$ and atmospheric air were injected. On the other hand, a difference was observed $(\mathrm{p}=0.025$ and $p=0.009$, respectively) between the control subgroups versus $\mathrm{CO}_{2}$ and atmospheric air subgroups Still analyzing the graph, an outlier was noted at the sample, which was considered, as it didn't affect the study's result. There was no difference $(\mathrm{p}>0.05)$ in the 5 kDa CGRP quantification among subgroups (Figure 7).

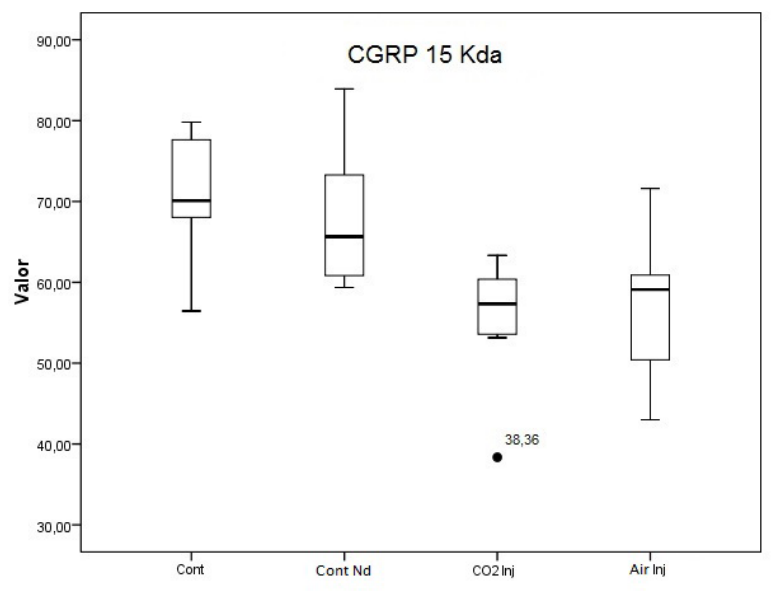

FIGURE 6 - 15 kDa CGRP neuropeptide quantification by Western blotting. Subgroups: Cont $=$ Control; ContNd $=$ Control with Needle; $\mathrm{CO}_{2}$ Inj $=\mathrm{CO}_{2}$ Injection; AirInj $=$ Atmospheric Air Injection .

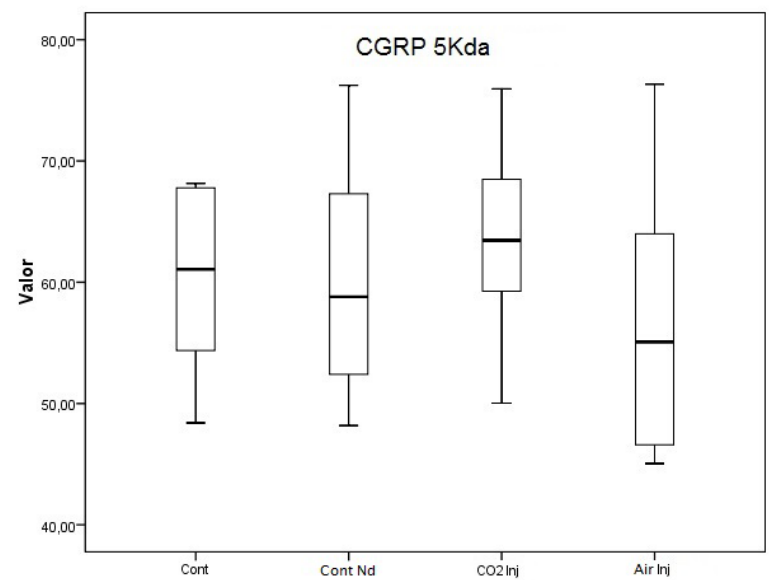

FIGURE 7 - 5 kDa CGRP neuropeptide quantification by Western blotting. Subgroups: Cont $=$ Control; ContNd $=$ Control with Needle; $\mathrm{CO}_{2} \mathrm{Inj}=\mathrm{CO}_{2}$ Injection; AirInj $=$ Atmospheric Air Injection .
The graph concerning SP neuropeptide quantification showed similar behavior and same hypothesis as the ones described for $15 \mathrm{kDa}$ CGRP Group (Figure 8). Neuropeptide quantification in Control Subgroup (Cont) did not differ from Control with Needle Subgroup (ContNd). The same happened for subgroups receiving $\mathrm{CO}_{2}$ or Atmospheric Air Injection. A significant difference ( $\mathrm{p}=0.013$ and 0.003 , respectively) occurred between control versus $\mathrm{CO}_{2}$ or Atmospheric Air Injection subgroups. Also, an outlier was noted at the sample, which was considered as it didn't affect the study's result.

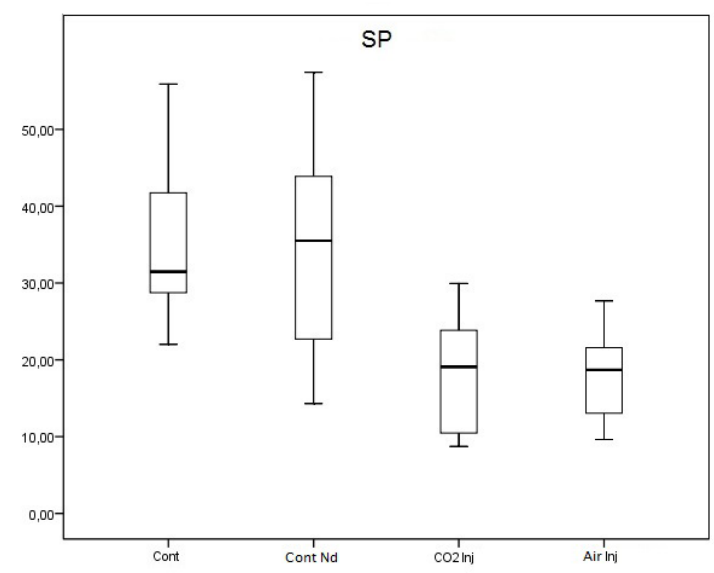

FIGURE 8 - SP neuropeptide quantification by Western blotting. Subgroups: Cont $=$ Control; ContNd $=$ Control with Needle; $\mathrm{CO}_{2} \mathrm{Inj}=$ $\mathrm{CO}_{2}$ Injection; AirInj = Atmospheric Air Injection.

After the first analyses, the Kolmogorov Smirnov Test has been applied to the three groups: $15 \mathrm{kDa}$ CGRP ( $\mathrm{p}=0.976), 5$ $\mathrm{kDa}$ CGRP $(\mathrm{p}=0.907)$ and SP $(\mathrm{p}=0.848)$ and none of the samples presented normality, according to the p-values.

The Wilcoxon Mann Whitney Test was then applied, which compared subgroups two by two.

Regarding the $15 \mathrm{kDa}$ CGRP sample, the only subgroups that did not present a significant difference in neuropeptide quantification were $\mathrm{CO}_{2}$ Inj compared to AirInj ( $\mathrm{p}=0.749$ ). Cont and ContNd subgroups showed a difference in neuropeptide quantification when compared to the other subgroups.

The next tested sample was $5 \mathrm{kDa}$ CGRP, which did not present statistically significant difference in neuropeptide quantification in any of the subgroups.

To conclude the analyses, the SP sample was tested, which did not present any difference in neuropeptide quantification between Cont and ContNd subgroups $(\mathrm{p}=0.949)$, and in the comparison between $\mathrm{CO}_{2}$ Inj and AirInj ( $\left.\mathrm{p}=0.949\right)$. 


\section{Discussion}

There is arteriolar vasodilation with formation of a papule and erythema in neurogenic inflammation. Any damage or stimulus to the skin may trigger neurogenic inflammation. Exudation of plasma and neurogenic vasodilation may be inhibited by blocking the nerve impulse and its conduction, mast cell stabilization, blocking capsaicin receptors, blocking ionic channels, with use of anti-inflammatory steroids, depletion of neurotransmitters and pre-synaptic inhibition ${ }^{12}$.

Due to the importance of CGRP and SP neuropeptides in the skin, this study aimed at investigating the influence of carbon dioxide $\left(\mathrm{CO}_{2}\right)$ on the release of these neuropeptides, which helps clarify the mechanisms leading to the increase in vascular perfusion by $\mathrm{CO}_{2}$.

Neuropeptides are easily released by nerve endings, and their availability standard in skin and cell internalization are not studied enough $^{13,14}$. Therefore, the process of hair removal could be a decisive factor of cutaneous neuropeptide release, since the removal of hair by any method also implies microtraumas on the animal's skin.

Since there are no studies in the literature determining the degradation time of neuropeptides in the interstitium of the skin, a pilot study was necessary to determine how long these substances take to return to physiological concentrations in the skin after hair removal. SP and CGRP return to basal values in up to 60 minutes after the generation of a single stimulus. A 60-minute time was thus established for the beginning of the experiment after hair removal, when concentrations of both neuropeptides had already been undoubtedly in physiological levels. Neither Drucker et $a l .{ }^{15}$ nor Rajkovic et al. ${ }^{16}$ claimed waiting for any period of time after hair removal, which could represent a bias in neuropeptide quantification in the skin.

Regarding gas injection, another pilot study was necessary (non-published data) to determine the time for detecting $\mathrm{SP}$ and CGRP neuropeptides in rat skin after $\mathrm{CO}_{2}$ and Atmospheric air injection. Accordingly, to determine the moment of sacrificing and removal of partial skin, a specific waiting time was established for each neuropeptide group: 14 minutes for SP and 21 for CGRP.

For $\mathrm{CO}_{2}$ application, this study used the subcutaneous injection technique because according to a previous study, this technique promoted greater cutaneous distension and less resistance to needle puncturing than the intradermal application technique. This corroborates the findings of Ferreira et al. ${ }^{17}$, which emphasize the need for research to compare intradermal and subcutaneous injections, as well as to define the volume of gas used and the frequency of treatment sessions. In this study, a 80 $\mathrm{ml} / \mathrm{min}$ flow for 10 seconds was standardized, in a single point and using a hypodermic needle at 90 degrees from the skin.

The experimental model used the rat's dorsal region, which is 900 to $1.000 \mu \mathrm{m}$ thick and has abundant hair follicle above $500 \mu \mathrm{m}$ deep. According to Rajkovic et al. ${ }^{16}$ nerve endings are concentrated on the epidermis and on the upper half of the dermis and the hair follicles. For being richly endowed with nerves and abundant in neuropeptides, they can mask the analysis of subtler events on the skin surface. Thus, this study used an electrical dermatome so that the partial skin would have a constant thickness $(500 \mu \mathrm{m})$ and that there was no difference in volume among samples, or that they would not inadvertently come with subcutaneous tissue or panniculus carnosus.

Dorsal root ganglia neuronal cell bodies synthesize CGRP by the transcription of calcitonin/CGRP gene, where a $15 \mathrm{kDa}$ precursor molecule called pro-CGRP is synthesized in the endoplasmic reticulum and processed in the Golgi apparatus. Pro-CGRP is transported antidromically down the axon to the free cutaneous endings, then cleaved into CGRP (active form), with approximately $5 \mathrm{kDa}$, and released in the interstitium upon a local stimulus. Mishima et al. ${ }^{18}$ investigated the influence of CGRP in ischemic limbs revascularization in rats and quantified pro-CGRP to prove the release and increase in CGRP production during the experiment. This study demonstrated a total depletion of proCGRP levels in skin, which suggests cleavage of this precursor and CGRP release in the skin.

Neurogenic inflammation is involved in physiological and pathological processes of wound healing; therefore, the possibility of modulating its initial stages - delaying, inhibiting or stimulating it - would bring the perspective of controlling these processes, eventually optimizing the time required for normal wound healing and correcting pathological wound healing. The results of this study show that carbon dioxide injections promote a decrease in the amount of pro-CGRP and SP neuropeptides, corroborating the findings of Vause et $a l^{2}{ }^{2}$ who observed that $\mathrm{CO}_{2}$ can inhibit CGRP release by trigeminal neurons. Also, and surprisingly, subcutaneous injection of atmospheric air, which also decreases the amount of neuropeptides, open perspectives for researches with air injection as to modulate neuropeptides and thus neurogenic inflammation in the skin. In this context, the use of the carbon dioxide injection technique could be beneficial as an adjunct therapy by modulating the secretion of neuropeptides, controlling cutaneous diseases of neuropeptidergic source, such as psoriasis, atopic dermatitis and keloid, besides the classical treatment. In conclusion, carbon dioxide and atmospheric air 
injections in rat skin caused a local decrease in the amount of Substance $\mathrm{P}$ and pro-Calcitonin Gene-Related Peptide (proCGRP) neuropeptides.

\section{Conclusion}

Subcutaneous injection of $\mathrm{CO}_{2}$ and atmospheric air decreased the amount of Substance P and pro-Calcitonin GeneRelated Peptide $(15 \mathrm{kDa})$ neuropeptides in rat skin.

\section{References}

1. Brandi C, D'Aniello C, Grimaldi L, Bosi B, Dei I, Lattarulo P, Alessandrini C. Carbon dioxide therapy in the treatment of localized adiposities: clinical study and histopathological correlations. Aesthetic Plast Surg. 2001;25(3):170-4.

2. Vause C, Bowen E, Spierings E, Durham P. Effect of carbon dioxide on calcitonin gene-related peptide secretion from trigeminal neurons. Headache. 2007;47(10):1385-97.

3. Casale TB, Romero FA, Spierings EL. Intranasal noninhaled carbon dioxide for the symptomatic treatment of seasonal allergic rhinitis. $\mathrm{J}$ Allergy Clin Immunol. 2008;121(1):105-9.

4. Bellamy JL, Cady RK, Durham PL. Salivary levels of CGRP and VIP in rhinosinusitis and migraine patients. Headache. 2006;46(1):24-33.

5. Liang Z, Engrav LH, Muangman P, Muffley LA, Zhu KQ, Carrougher GJ, Underwood RA, Gibran NS. Nerve quantification in female red Duroc pig (FRDP) scar compared to human hypertrophic scar. Burns. 2004;30(1):57-64.

6. Hochman B, Nahas FX, Sobral CS, Arias V, Locali RF, Juliano Y, Ferreira LM. Nerve fibres: a possible role in keloid pathogenesis. $\mathrm{Br}$ J Dermatol. 2008;158(3):651-2.

7. Schmelz M, Petersen LJ. Neurogenic inflammation in human and rodent skin. News Physiol Sci. 2001;16:33-7.

8. Steinhoff M, Ständer S, Seeliger S, Ansel JC, Schemelz M, Luger T. Modern aspects of cutaneous neurogenic inflammation. Arch Dermatol. 2003;139:1479-88.

9. Ferreira LM, Silva EK, Jaimovich CA, Calazans D, Silva ER, Furtado F, Cosac O, Nader P, Corrêa WEM. Carboxytherapy: seeking evidence for its use in plastic surgery and dermatology. Rev Bras Cir Plást. 2012;27(3):350-1.

10. Bradford MM. A rapid and sensitive method for the quantitation of microgram quantities of protein utilizing the principle of proteindye binding. Anal Biochem. 1976;72:248-54.

11. Chadi G, Silva C, Maximino JR, Fuxe K, da Silva GO. Adrenalectomy counteracts the local modulation of astroglial fibroblast growth factor system without interfering with the pattern of 6-OHDAinduced dopamine degeneration in regions of the ventral midbrain. Brain Res. 2008;1190:23-38.

12. Kalil-Gaspar P. Neuropeptides in the skin. An Bras Dermatol. 2003;78(4):483-98.

13. Brain SD, Cambridge $\mathrm{H}$. Calcitonin gene-related peptide: vasoactive effects and potential therapeutic role. Gen Pharmacol. 1996;27(4):607-11.
14. Weidner C, Klede M, Rukwied R, Lischetzki G, Neisius U, Skov PS, Petersen LJ, Schmelz M. Acute effects of substance P and calcitonin gene-related peptide in human skin--a microdialysis study. J Invest Dermatol. 2000;115(6):1015-20.

15. Drucker M, Cardenas E, Arizti P, Valenzuela A, Gamboa A. Experimental studies on the effect of lidocaine on wound healing. World J Surg. 1998;22(4):394-7.

16. Rajkovic V, Matavulj M, Johansson O. The effect of extremely low-frequency electromagnetic fields on skin and thyroid amineand peptide-containing cells in rats: an immunohistochemical and morphometrical study. Environ Res. 2005;99(3):369-77.

17. Ferreira JC, Haddad A, Tavares SA. Increase in collagen turnover induced by intradermal injection of carbon dioxide in rats. J Drugs Dermatol. 2008;7:201-6.

18. Mishima T, Ito $\mathrm{Y}$, Hosono $\mathrm{K}$, Tamura $\mathrm{Y}$, Uchida $\mathrm{Y}$, Hirata M, Suzsuki T, Amano H, Kato S, Kurihara Y, Kurihara H, Hayashi I, Watanabe M, Majima M. Calcitonin gene-related peptide facilitates revascularization during hindlimb ischemia in mice. Am J Physiol Heart Circ Physiol. 2011;300(2):H431-9.

\section{Acknowledgements}

To Top Laser Brasil, which provided the carboxytherapy equipment (Ares Carboxiterapia - Ibramed LTDA) for this study; the physical therapists Arainy Antunes and Silvilena Bonatti and the plastic surgeons Guilherme A. Lapin and Paulo Rogério Quieregatto who directly assisted in the experimental procedures.

\section{Correspondence:}

Lydia Masako Ferreira

Departamento de Cirurgia/Disciplina de Cirurgia Plástica

Universidade Federal de São Paulo

Rua Napoleão de Barros, $715 / 4^{\circ}$ andar

04023-002 São Paulo - SP Brasil

Tel.: (55 11)5539-0824

Fax: (55 11)5571-6579

lydiamferreira@gmail.com

Received: Dez 12, 2013

Review: Feb 14, 2014

Accepted: March 11, 2014

Conflict of interest: none

Financial source: none

${ }^{1}$ Reseach performed at Experimental Surgery Laboratory, Department of Surgery, Paulista School of Medicine (EPM), Sao Paulo Federal University (UNIFESP), Sao Paulo-SP, Brazil. Part of Master degree thesis, Postgraduate Program in Plastic Surgery, UNIFESP. Tutor: Lydia Masako Ferreira. 